\title{
Correction to: MIT's moral machine project is a psychological roadblock to self-driving cars
}

\author{
Heidi Furey ${ }^{1} \cdot$ Scott Hill ${ }^{2}(0$
}

Published online: 2 November 2020

C) Springer Nature Switzerland AG 2020

\section{Correction to: Al and Ethics}

https://doi.org/10.1007/s43681-020-00018-z

A funding note had accidentally been omitted in the original publication.

The missing funding note is given here:

"This material is based upon work supported by the National Science Foundation under Grant No. SES-1734521."

The original article has been corrected.

The original article can be found online at https://doi.org/10.1007/ s43681-020-00018-z.

Scott Hill

hillscottandrew@gmail.com

1 Department of Philosophy, Manhattan College, 4513

Manhattan College Parkway, Riverdale, NY 10471, USA

2 CU Boulder Philosophy, Hellems 169 UCB 232, Boulder, CO 80309-0232, USA 